\title{
Toplumsal Cinsiyet Rolleri ve Tüketim Kültürü
}

\author{
Rafet BEYAZ ${ }^{1}$ \\ Esra KARAKUŞ UMAR ${ }^{2}$ \\ Şerife KILIÇARSLAN ${ }^{3}$
}

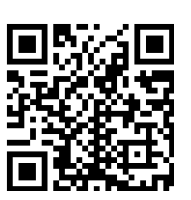

\begin{tabular}{ccc}
\hline Geliş Tarihi/ Received & Kabul Tarihi// Accepted & Yayın Tarihi/ Published \\
17/04/2020 & $14 / 10 / 2020$ & $23 / 10 / 2020$ \\
\hline Citation/Atıf: Beyaz, R. Karakuş Umar, E. ve Kilıçarslan, S., (2020), Toplumsal Cinsiyet \\
Rolleri ve Tüketim Kültürü, Atatürk Üniversitesi İktisadi ve İdari Bilimler Dergisi, 34(4): Sayfa: \\
1311-1331, DOI: https://doi.org/10.16951/atauniiibd.722244
\end{tabular}

Öz: Toplumsal cinsiyet rolleri, kadın ya da erkeğin toplumsal statülerinin bir sonucu olarak inşa edilmiş beklentileri temsil etmektedir. Ataerkil sistemde ev hanımı olan bir anne, çocuğuna bakıp ev işleriyle ilgilenirken çalışan bir baba, evin maddi ihtiyaçlarını karşılamaktadır. Ataerkil sistemde kadın, kamusal alana karışmamış özel alanda iken erkek, kamusal alandadır. Ancak günümüzde geleneksel roller yerini yeni toplumsal cinsiyet rollerine bırakmıştır. Ekonomik sistemdeki değişimin etkisiyle kadının eğitim ve iş hayatına dahil olması, onun kamusal alanda bulunmasını sağlamışırı. Artık kamusal alanda hem kadınlık hem de erkeklik rolleri ekonomik sistemin gölgesinde yeniden inşa edilmektedir. Modern toplumun kültürel özelliklerinin yanında tüketim kültürü de bireylere yeni statüler ve roller atfetmektedir. Böylelikle bireyler hem içinde bulundukları kültürün özelliklerini hem de tüketim kültürünün özelliklerini bir arada yaşamaktadırlar. $\mathrm{Bu}$ çalışmada üniversite öğrencilerinin toplumsal cinsiyet rolleri ile tüketim kültürü davranışlarını nasıl ilişkilendirdiğinin ve inşa ettiğinin ortaya çıkarılması amaçlanmıştır. Karma araştırma metodunun kullanıldığı çalışmada plansız satın alma davranışı ölçeği ile hedonik tüketim ölçeğinden yararlanılmıştır. Mülakatlar sırasında yarı yapılandırılmış görüşme formu kullanılmış ve otuz öğrenci ile derinlemesine görüşmeler gerçekleştirilmiştir. Araştırma sonucunda cinsiyet ile hedonik tüketim ve plansız satın alma davranışları arasında çeşitli farklılıklar tespit edilmiştir. Ayrıca görüşmeci olarak araştırmaya katılan kadın ve erkek görüşmecilerin, toplumsal cinsiyet rollerini farklı şekillerde inşa ettikleri ortaya çıkmıştır.

Anahtar Kelimeler: Tüketim Kültürü, Cinsiyet Rolleri, Hedonik Tüketim

\section{Gender Gender Roles and Consumption Culture}

Abstract: Gender roles represent the expectations developed as a result of the social status of men or women. In the patriarchal system, a mother is a housewife caring for her children and dealing with the household chores, while a father meets the financial needs of the house. In the patriarchal system, the female is confined in the private space, not in the public space, while the male is in the public space. Today, however, traditional roles are replaced by new gender roles. In

\footnotetext{
${ }^{1}$ Dr. Öğr. Üyesi, Atatürk Üniversitesi, Oltu Beşeri ve Sosyal Bilimler Fakültesi, İşletme Bölümü, https://orcid.org/0000-0002-0026-5346

${ }^{2}$ Dr. Öğr. Üyesi, Atatürk Üniversitesi, Oltu Beșeri ve Sosyal Bilimler Fakültesi, Sosyal Hizmet Bölümü, https://orcid.org/0000-0003-1764-9394

${ }^{3}$ Arş. Gör., Atatürk Üniversitesi, Oltu Beşeri ve Sosyal Bilimler Fakültesi, Bankactlık ve Finans Bölümü, https://orcid.org/0000-0002-5715-3417
} 


\title{
Toplumsal Cinsiyet Rolleri ve Tüketim Kültürü
}

\begin{abstract}
line with the effect of the change in the economic system, the involvement of women in education and business life ensured their presence in the public space. Now the roles of both femininity and masculinity in the public space are being rebuilt in the shadow of the economic system. In addition to the cultural characteristics of modern society, comsumption culture also assigns new statuses and roles to individuals. Thus, individuals experience both the characteristics of the culture they are in and the characteristics of the consumer culture. In this study, it has been aimed to reveal how undergraduates develop consumer culture behaviors and relate them with gender roles. In this study, conducted with mixed research design, the unplanned purchasing behavior scale and the hedonic consumption scale have been used. A semi-structured interview form has been used during the interviews, and in-depth interviews have been conducted with 30 undergraduates. As a result of the study, several differences between gender and hedonic consumption and unplanned purchasing behaviors have been identified. In addition, the female and male participants included in the research have been found to construct their gender roles in different ways.

Keywords: Consumption Culture, Gender Roles, Hedonic Consumption
\end{abstract}

\section{EXTENDED SUMMARY}

\section{Purpose of the Study}

This study mainly aims to determine the relationship between gender roles and consumption culture of university students.

\section{Research Questions}

- Do hedonic consumption tendencies differrentiate in terms of gender?

- Do unplanned purchasing tendencies differrentiate in terms of gender?

- Do gender and consumer culture trends differentiate?

\section{Literature Review}

The research has focused on studies that has investigated the impact of consumer culture on the individuals. For this purpose, studies which have investigated how males and females behave in terms of consumption behavior have been reviewed (Bauman, 2018, Turner, 2011, Bocock, 2014, Baudrillard, 2004). Furthermore, it has revealed that the existence of men and women in the social sphere through their "gender roles", and the fulfillment of the expectations of the genders can be observed in their behaviors (Odabaşı and Barış, 2006). As a result, gender roles are constantly being reconstructed in the social sphere (Butler, 2012), and this process of reconstruction is formed by the effects of the current social system. Thus, the impact of consumer culture on individuals can be evaluated through the behaviors they perform. In these studies, the attitudes of female consumers that differ from male consumers are remarkable.

\section{Method}

Primary data has utilized to test the research objectives. In this context, both quantitative and qualitative methods have been used in a mixed manner. The scales have prepared within the scope of quantitative method consist of two parts. The first part contains 7 items to determine the demographic characteristics and consumption trends of the participants. In the second part, the hedonic consumption scale developed by Arnold and Reynolds (2003:77-95) has used to identify participants' hedonic consumption tendencies, and unplanned purchasing 
scale developed by Weun, Jones and Beatty (1997:306-307) has used to identify the impulsive purchasing trends.

In qualitative analysis, in-depth interviews has been conducted to evaluate the data obtained as a result of quantitative analysis. Within the scope of this analysis, there are items about whether the questions asked on the scales have been understood as intended as well as the items for the evaluation of the research questions. A semi-structured interview form has been used in the interviews.

The study population consists of the undergraduates who had been studying at the Atatürk University Oltu Faculty of Humanities and Social Sciences. The number of undergraduates had been studying at the faculty was 350 at the time of the study, between November 2019 and January 2020. The table of "Acceptable Minimum Sample Sizes for Different Population Sizes" (Gegez, 2010: 225) has used to determine the sample size. Accordingly, the sample should be 196 for the population of 350 , with a $95 \%$ confidence interval. Within this framework, 200 questionnaires have been collected by using the convenience sampling.

Within the scope of the qualitative study, interviews were conducted in March 2020 with 30 undergraduates who had been selected from the study population by simple random method.

\section{Conclusion and Evaluation}

The quantitative study has revealed a significant difference between unplanned purchasing and the gender variable. In this regard, the genders of participants have not been allowed for any discrimination. While some female participants have stated to have unplanned purchasing behavior, some others have stated that they avoide unplanned shopping, emphasizing their inadequate economic status. This suggests that female participants cannot be generalized in terms of unplanned shopping. However, male participants approach the issue of unplanned shopping with a clearer attitude and avoid unplanned shopping.

In addition, significant differences have been found in the quantitative research between gender and hedonic consumption trends. Qualitative research has also revealed findings supporting this result. Male participants generally have the idea of "I'll go shopping if I need to". This suggests that the male participants' "results-oriented perspective" is not as open to the impact of consumer culture as that of female participants. This is related to how females and males make sense of the concept of "need". In fact, both parts go shopping in order to meet their needs. However, only women can consider "shopping" a need in times of "unhappiness". Therefore, the basis of hedonic and unplanned shopping behavior is the differentiation of what is seen as a need by males and females. However, while female participants in the study have an overall idea of the need, the consensus of males about what the need is are remarkable from the research perspective. Finally, hedonic consumption behavior and unplanned purchasing behavior have been found to be intertwined in the study. During the interviews, 


\section{Toplumsal Cinsiyet Rolleri ve Tüketim Kültürü}

it had been being observed that there were comments regarding unplanned purchasing behavior, even while talking about hedonic consumption.

\section{Giriş}

Tüketim kültürünün etkisiyle birlikte bireyler, üretmekten çok tüketmeyi odak noktası haline getirmişlerdir. Tüketim kültürünün bireyler üzerinde yarattığı etki dikkate alındığında cinsiyet değişkeninin süreçte oynadığı roller ve toplumsal cinsiyet rollerinin tüketim kültüründen etkilenerek yeniden inşa edilişi sorgulanması gereken bir konudur. Öyle ki tüketim kültürü üzerine çalışmaların yapıldığı ilk dönemde kadınların tüketim harcamalarında oynadığı role bağlı olarak hedef kitle olduğu vurgusu günümüzde yerini her iki cinsiyetin de tüketim kültürünün devamlılığ için önemli olduğu fikrine bırakmıştır. Bu fikrin önemli temsilcilerinden olan Turner (2011) ve Bocock (2014), tüketim kültürünün artık bir cinsiyeti değil tüketim yapabilecek tüm insanlığı hedef aldığını belirtmişlerdir.

Tüketim kültürünün cinsiyet ayırmadan tüketim yapabilecek potansiyeli olan herkesi hedef alması fikri, cinsiyetlere nasıl seslendiği soru işaretlerini ortaya çıkarmaktadır. Tüketim kültürünün cinsiyetlere seslenme şeklinin toplumsal cinsiyet rolleri üzerinden belirlendiğini öne süren Odabaşı ve Barış (2006), erkekleri akılcı davranışlar sergileyen kadınları ise duyguları ile hareket eden olarak sınıflandırmışlardır. Bu sınıflandırmaya göre tüketim için erkeklere akılcı davranışlar sergilediklerini vurgulayan içerikler üretilirken, kadınlara seslenmek adına toplumsal cinsiyet rollerinin işaret ettiği şekilde duygusal içerikler üretebilir. Burada "duygusal olan kadın" ifadesinde, duygularını dışa vuran kadın olarak düşünüldügü farz edilmektedir. Duygusallık, kadının alışveriş deneyiminde kendisini göstermektedir. Örneğin alışveriş yapan kadın, alışveriş yapan bir erkeğe göre daha fazla haz aldığını belirtebilmektedir (Özdemir ve Yaman, 2007: 88-89). Ancak belirtilmelidir ki "daha fazla haz almak" ifadesi kadın üzerinden üretilen bir tüketim kültürü söylemi halini almaktadır. Böylelikle tüketimin, sosyal hayattaki kadınlık rollerinin bir gerekliliği şeklinde dayatıldığı söylenebilir.

Bilindiği üzere toplumsal cinsiyet rolleri, kültürel sistemin inşasıyla var olmaktadır. Kadın doğulmaz kadın olunur ifadesinde olduğu gibi De Beauvoir (1949), kadın olmayı inşa sürecine bağlamaktadır. Öyle ki bu bir cinsiyet kurgusudur ve değişmektedir (Butler, 2012). Dolayısıyla kadın ve erkekten o toplum yapısında ne bekleniyorsa cinsiyet rolleri de bu şekilde yeniden ve yeniden toplumsal hayat üzerinden inşa edilmektedir. Örnekle günümüzde kadının eşiyle birlikte aile ekonomisine katkısı beklenirken çocuklarına da bakması ve ev işlerinden de haberdar olması beklenmektedir. $\mathrm{Bu}$ sınıflandırmadan yola çıkıldığında tüketim kültürünün bireylere atfettiği roller, ataerkil düzenin etkisinden bağımsız düşünülemez.

Ataerkilliğin ve kapitalizmin etkisinde kadınlık ve erkeklik rolleri şekillenmektedir. Böylelikle toplumsallaşma süreçlerinden biri olan gençlik 
dönemi, çocukluk döneminden sonra (Sormaz ve Yüksel, 2012), bireylerin ataerkillik ve kapitalizmin etkisinde toplumsal rollerini şekillendiği bir süreçtir. $\mathrm{Bu}$ dönemin en önemli özelliği, çocukluktan çıkan bireyin yetişkinliğe geçiş sürecinde kendi kimliğini ve toplumsal alanda işgal ettiği yeri tanımlama çabasıdır. Ayrıca kronolojik olarak da 15-24 yaş arasını ifade eden bu dönem, bazı çalışmalarda tüketim kültürünün hedefi olarak değerlendirilmiştir (bkz. Köroğlu, 2014; Tükel, 2014). Şener(1997:16)'e göre tüketim kültürünün gençleri hedef olarak belirlemesinin temelinde toplumsal cinsiyet rolleri yatmaktadır. Ona göre toplumsallaşma sürecinin bu evresinde gençler, anne ve babalarının dışındaki bireyleri rol model almakta ve kimliklerini bu yönde yeniden inşa etmektedir. Bu açıdan tüketim kültürünün de etkilerine açık hale gelmektedirler.

Tüketim kültürünün kendisinin, bireylere hitap etmek gibi bir tutumunun olmadığını bu noktada belirtmek gerekmektedir. Tüketim kültürü, bir hitap sistemi olmaktan daha fazlasıdır. Zorlamanın yer aldığı bir ahlaka sahip olan bir sistem ve toplumsallaşma tarzıdır diyen Baudrillard (2004: 95)'ın da dediği gibi tüketim kültürü, tüketicilere hitaptan ziyade tüketim için alıştırmaların yer aldığı bir toplumsal değerler sistemidir. Öyle ki bu değerler sisteminde "curcuna ve telaş" söz konusudur.

Bauman (2018: 250) tavşan av1 örneği üzerinden tüketim toplumunun bireyler üzerinde yarattı̆g 1 tahriki anlatmaya çalışmaktadır. Tüketim kültürü, bireyler üzerinde yarattı̆̆ tahrikle tüketime yönlendirilmektedir. Nasıl ki tavşan avına çıkıldığında haz veren onu yakalamak değil onu kovalamak ise tüketim kültüründe de tüketimcilik böyledir. Amaç, tüketim değil tüketimciliktir.

Neticede tüketim kültürünün bir sistem ve ahlaki bir düzen olduğu düşünüldüğünde o sistem içerisinde yaşayanların "hazla" ödüllendirildiği ya da sistem içerisinde dahil olamayanların da "dışlandığı" bir mekanizmadan söz edilebilir. Ferguson (1996: 205), hazzı tanımlarken kapitalist toplumların üretimi sürekli genişleterek tüketenlerin de bu sınırları belirsiz alandaki davranışlarını anlatmaktadır. Yani bu toplumda tüketim, Baudrillard (2004)'a göre ihtiyaçların tüketimi değil anlamların tüketimidir. Öyle ki satın alınan ya da alınması arzulanan, şeyin kendisi değil ardında yaratılan anlamlardır. Dolayısıyla tüketilen, bireyin sahip olmak istediği anlamlarla yakından ilişkilidir. Ürünlerin satın alınmasında ardındaki anlamın belirleyici olduğunu vurgulayan Levy (1959), 'İnsanlar ürünleri sadece bu ürünle yapabilecekleri şeyler için değil, bu ürünün kendilerine kattığı anlam için de satın alırlar.' ifadesini kullanmıştır.

Hedonik satın alma davranışının bir parçası olan anlık satın alma davranışına göre yine haz alma ön plandadır (Yiğit, 2014: 17). Anlık satın alma davranışında plansızlık söz konusudur. Anlık satın alma tanımına göre mağazaya girmeden önce satın alma niyeti olmamasına rağmen bireyin, mağazaya girmesiyle satın almak adına harekete geçmesi şeklinde tanımlanmıştır. Burada satın alma davranışı dürtüseldir ve kendiliğinden gerçekleşmektedir (Rook, 1987: 191). Rook ve Hoch(1985) anlık satın almayı, hazzın spontane bir şekilde gerçekleşmesi ile satın almanın da ortaya çıkması şeklinde tanımlamıştır. 


\section{Toplumsal Cinsiyet Rolleri ve Tüketim Kültürü}

Anlık satın alma davranışının kendi içinde dört farklı şekilde gerçekleştĭgi söylenebilir. Stern (1962: 59-60)'e göre ilki tamamıla plansız bir şekilde gerçekleşen "Tamamen plansız yapılan anlık satın alma" davranışıdır. İkincisi, "Hatırlamalarla yapılan anlık satın alma" şeklinde isimlendirilir ve birey, alışveriș esnasında satın alması gerektiğini hatırlar. Üçüncü anlık satın almada mantık ön plandadır. Satın alma isteği alışverişte gerçekleşir. Deneyim söz konusu değildir. Akıl yürütme görülür. Bu satın alma davranışı "Önerilerle yapılan anlık satın alma" şeklinde isimlendirilmiş̧ir. Son olarak "Daha önceden planlanmış anlık satın alma" davranışında ise birey, satın alma fikrindedir ve alışveriş sırasındaki etkiler onun satın almasına etki eder. Örneğin anlık anonslar bu konuda tüketiciyi etkilemektedir.

Hedonik ve plansız satın alma davranışlarının gerçekleşmesinde hazzın dürtüsel ve belirleyici etkide olması, araştırma sorularının da niteliğini etkilemiştir. Çalışmada yer alan hedonik ve plansız satın alma ölçekleri, araştırmanın seyrini belirlerken cinsiyet değişkeni çerçevesinde görüşmecilerin satın alma deneyimlerini toplumsal rolleri ile etkileşimleri bağlamında değerlendirmek hedeflenmektedir. Bu sebeple araştırmada hedonik ve plansız satın alma davranışları çerçevesinde bireylerin satın alma davranışlarında toplumsal cinsiyet rollerini yeniden inşa etme süreçleri ortaya konulmaya çalışılmıştır.

\section{Literatür Taraması}

Hedonik tüketim kavramını ortaya atan Hirschman ve Holbrook (1982)'a göre önemli olan ürünlerin deneyimleri sırasındaki duygu durumlarıdır. Söz konusu deneyim, bireylerin tüketime yönelmelerine neden olmaktadır. Ancak belirtilmelidir ki hedonik tüketimde, tüketimin kendisinden ziyade alışveriş ortamında bulunmak dahi önemsenmektedir. Öyle ki tüketici yeni tüketim ürünleri hakkında bilgi sahibi olabilmektedir (Chang vd., 2004: 188). Ayrıca hedonik tüketimde satın alınan ürünün, herhangi bir fonksiyonel özelliğinin olup olmamasının bir değeri yoktur (Schaugnessy-O'Shhaugnessy, 2002: 527).

Hedonik tüketim ölçeğini kullanan araştırmalar incelendiğinde Scherhorn (1990), kadınların erkeklere göre alışverişten daha çok zevk aldıkları sonucuna varmıştır. Özdemir ve Yaman (2007) çalışmalarında kadın ve erkek tüketicilerin alışveriş sırasında farklı davranış kalıplarını benimsediklerini ortaya koymuştur. Kadının erkeğe göre alışverişte daha çok hedonik davranışlar sergilediği literatürü genişletilebilir (Babacan, 2001; Arnold ve Reynolds, 2003; Altunışık ve Çall1, 2004).

Aydın (2010) hedonik alışveriş alışkanlığının tüketicinin cinsiyete göre farklılaştığını tespit ederek, kadınların erkeklere oranla hedonik tüketime daha istekli olduğunu belirtmiştir. Kükrer (2011)'in üniversite gençliği üzerinde yaptığı çalışması ve Özgüven (2013)'in hedonik tüketim ile cinsiyet ve gelir ilişkisi çalışması hedonik tüketimle cinsiyet arasında anlamlı bir ilişkinin bulunduğu görülmektedir. Doğan, Gürler ve Ağcadağ (2014) Tokat il merkezinde 
yaşayan tüketicilerin cinsiyet, yaş, medeni durum ve eğitim durumuna göre hedonik tüketim yapma durumu istatistiki olarak farkl1l1k gösterirken, aylık gelir ve meslek grupları bakımından farklılıklar görülmediğini tespit etmişlerdir. Aytekin ve Ay (2015) çalışmalarında hedonik tüketim eğiliminin cinsiyet, yaş ve gelir grupları açısından, anlık satın alma davranışının ise cinsiyet ve meslek grupları açısından farklı1ık gösterdiğini saptamışlardır. Bulut, Çimrın Kökolan ve Doğan (2017) cinsiyet ve sürdürülebilir tüketim davranışı arasında bir ilişki olduğunu, kadınların hem genel davranışta hem de ürünleri yeniden kullanma eğiliminde daha yüksek düzeyde sürdürülebilir tüketim davranış1 gösterdiğini belirtmiştir. Kim (2019) çalışmasında kahve tüketimi ile cinsiyet arasında anlamlı bir farkl1l1k olduğunu tespit etmiştir.

Çalışmada kullanılan diğer bir ölçek olan plansız satın alma davranışı ölçeğinin yer aldığı çalışmalara bakıldığında cinsiyet ve anlık satın alma davranışı arasında ilişki olduğu sonucuna varılmıştır (Armağan vd., 2019). Ancak Yücel (2018: 327)'in de çalışmasında belirttiği gibi genel anlamda satın alma davranışı ile toplumsal cinsiyet rolleri arasında bağlantı kuran araştırmaların sayısı fazla değildir. Tifferet ve Herstein (2012) kadınların marka bağımlılı̆̆ının, hedonik tüketimin ve dürtüsel satın almaların erkeklere kıyasla daha yüksek olduğunu saptamıştır. Çakıcı ve Özdamar (2014) kültür turlarına katılan yerli turistlerin anlık satın alma davranışlarını incelemiş ve anlık satın alma ile cinsiyet arasında anlamlı bir farklılık olduğunu tespit etmiştir. Yücel (2018), yaptığı çalışmada toplumsal cinsiyet rollerinin satın alma kararı üzerindeki etkisini incelemiş ve Anova testi sonucuna göre toplumsal cinsiyet rolleri ile satın alma kararları arasında anlamlı bir farklılık gözlemlenmiştir. Erciş vd. (2019) çalışmalarında keşifsel satın alma davranışının hedonik tüketimi olumlu etkilediğini tespit etmişlerdir. Aynı zamanda çalışmada, hedonik tüketim davranışının keşifsel satın alma davranışı ile plansız satın alma davranışı arasında arac1 rolünün olduğu görülmektedir. Karaca (2019) öğrencilerin materyalist eğilimlerin ve anlık satın alma davranışlarının demografik özelliklere göre farklılaşıp farklılaşmadığını tespit etmeye çalışmış ve anlık satın alma davranışının cinsiyete göre farklılaştı̆̆ını tespit etmiştir.

\section{Araştırmanın Yöntemi}

Çalışmanın bu bölümünde araştırmanın amacı, soruları, ana kütlesi, örneklemi, örnekleme süreci, veri toplama aracı ve sinırlıliklarına yer verilecektir.

\subsection{Araştırmanın Amacı}

$\mathrm{Bu}$ çalışmanın temel amacı, üniversite öğrencilerinin toplumsal cinsiyet rolleri ile tüketim kültürü arasındaki ilişkiyi belirlemektir. $\mathrm{Bu}$ amaç doğrultusunda öğrencilerin cinsiyet rolleri ile tüketim kültürü davranışlarını nasıl ilişkilendirdiği ve tüketim kültürünün etkisinde toplumsal cinsiyet rollerini nasıl inşa ettiği belirlenmeye çalışılmaktadır. 


\section{Toplumsal Cinsiyet Rolleri ve Tüketim Kültürü}

\subsection{Araştırma Sorular}

Araştırma, keşfedici bir özellik taşımasından dolayı hipotezlere değil, araştırma sorularına dayanmaktadır. Bu kapsamda belirlenen araştırma soruları aşağıdaki gibidir.

- Cinsiyet açısından hedonik tüketim eğilimleri farklılaşmakta mıdır?

- Cinsiyet açısından plansız satın alma eğilimleri farklılaşmakta mıdır?

- Genel olarak cinsiyet ile tüketim kültürü eğilimleri farklılaşmakta midir?

\subsection{Veri Toplama Aracl}

Çalışmada veri toplamak amacıyla birincil ve ikincil verilerden faydalanılmıştır. Çalışmanın literatür taraması ve kavramsal çerçevesine yönelik bilgiler ikincil veriler çerçevesinde elde edilmiştir.

Çalışmanın amacını test etmek amaciyla birincil verilerden faydalanılmıştır. $\mathrm{Bu}$ kapsama karma olarak hem nicel hem de nitel yöntem kullanılmıştır. Nicel yöntem kapsamında hazırlanan anketler iki bölümden oluşmaktadır. Birinci bölümde katılımcıların demografik özellikleri ve tüketim eğilimlerini belirlemeye yönelik 7 soru bulunmaktadır. İkinci bölümde ise, katılımcıların hedonik tüketim eğilimlerini ve anlık satın alma davranışlarını belirlemeye yönelik iki farklı ölçek kullanılmıştır. Hedonik tüketim eğilimlerini belirlemek için Arnold ve Reynolds (2003: 77-95) tarafindan geliştirilen hedonik tüketim ölçeği, anlık satın alma eğilimini belirlemek için Weun, Jones ve Beatty, (1997: 306-307) tarafından geliştirilen plansız satın alma ölçeği kullanılmıştır. Her iki ölçek de 5'li likert ölçeği (1=Kesinlikle katılıyorum, 5=Kesinlikle katılmıyorum) ile ölçülmüştür. Veriler SPSS 20.0 istatistik programı yardımıyla analiz edilmiştir. Verilerin analizinde frekans analizi, $t$ testi, ANOVA ve açıklayıcı faktör analizi yapılmıştır.

Nitel analizde ise nicel analiz sonucunda elde edilen verilerin değerlendirilmesine yönelik derinlemesine mülakatlar yapılmıştır. $\mathrm{Bu}$ analiz kapsamında ise, ölçeklerde sorulan soruların istenilen şekilde anlaşılıp anlaşılmadığına ve hipotezlerin değerlendirilmesine yönelik sorular bulunmaktadır. Görüşmelerde yarı yapılandırılmış mülakat formuna yer verilirken araştırma sırasında "Koronavirüs" salgını olması sebebiyle görüşmeler, online ve telefon ile gerçekleştirilmiştir. Online görüşmelerde WhatsApp uygulaması kullanılmıştır. Görüşmecilerle birebir görüşmeler gerçekleştirilmiştir.

\subsection{Araştırmanın Ana kütlesi ve Örneklemi}

Çalışmanın ana kütlesi Atatürk Üniversitesi Oltu Beşeri ve Sosyal bilimler Fakültesinde okuyan öğrencilerden oluşmaktadır. Araştırmanın yapıldığı Kasım 2019-Ocak 2020 tarihleri arasında fakülteye devam eden öğrenci sayısının yaklaşık 350 civarında olduğu tespit edilmiştir. Örneklemin belirlenmesinde "Farklı Anakütle Büyüklükleri İçin Kabul Edilebilir Asgari Örneklem Büyüklükleri” (Gegez, 2010: 225) tablosundan yararlanılmıştır. Buna göre \%95 
güven aralığında, ana kütle 350 iken örneklemin 196 olması yeterli görülmektedir. $\mathrm{Bu}$ çerçevede belirtilen çalışama kolayda örnekleme tekniği kullanılarak tüm ana kitleden 200 kullanılabilir anket formu toplanmıştır.

Nitel çalışma kapsamında ise belirtilen ana kitle içerisinden basit tesadüfi yöntemle seçilen 30 kişi ile Mart 2020'de görüşmeler gerçekleştirilmiştir. Yarı yapılandırılmış soru formunun kullanıldığ 1 görüşmeler kapsamında ise nicel analiz sonucunda elde edilen bulgular değerlendirilmiştir.

\subsection{Araştırmanın Sinırlılıkları}

Zaman, maliyet ve erişim sorunu çalışmanın önemli bir kısıtı olarak değerlendirilmektedir. Aynı zamanda çalışmaya katılanların benzer demografik özellikler barındırması diğer önemli bir kısıt olarak değerlendirilmektedir. $\mathrm{Bu}$ durum da sonuçların tüm hedef kitleye genelleştirilmesinde önemli bir engel olarak görülmektedir.

Ayrıca derinlemesine mülakatların "salgın" sebebiyle yüz yüze gerçekleştirilememesi görüşmecilerin görüşmeler sırasındaki davranış ve mimiklerini değerlendirememeye neden olmuştur. $\mathrm{Bu}$ durum katılımcıların, söylemlerini destekleyip desteklemediğini anlamak açısından önemli bir sınırlılık olarak değerlendirilebilir.

\section{Araştırmanın Bulguları}

$\mathrm{Bu}$ başlık altında öncelikli olarak katılımcılar ve görüşmecilerin demografik özelliklerine yönelik bulgular değerlendirilecektir. Aynı zamanda çalışmada anlam karmaşası oluşmaması için nicel verilerin toplandığı kişiler katılımc1, nitel verilerin toplandığı kişiler ise görüşmeci olarak ifade edilmektedir.

\subsection{Demografik Özelliklere Göre Bulgular}

$\mathrm{Bu}$ başlık altında nicel veriler kapsamında toplanan anketlere yönelik demografik özellikler ile nitel çalışma kapsamında görüşmecilerin demografik özellikleri değerlendirilmektedir. Ayrıca görüşmecilerin plansız satın alma ve hedonik tüketime yönelik değerlendirmeleri de bu başlık altında ele alınmıştır.

Tablo 1: Katılımcıların Demografik Özellikleri ve Plansız Satın Alma Niyeti

\begin{tabular}{|c|c|c|c|c|c|c|c|}
\hline \multicolumn{2}{|c|}{ D. Özellikler } & $\mathbf{F}$ & $\%$ & \multicolumn{2}{|c|}{ D. Özellikler } & $\mathbf{F}$ & $\%$ \\
\hline \multirow{3}{*}{$\dot{\dot{\Xi}}$} & Kadın & 141 & 70,5 & \multirow{5}{*}{$\stackrel{\Xi}{\bar{\Xi}}$} & 1. Sinif & 28 & 14 \\
\hline & Erkek & 59 & 29,5 & & 2. Sinif & 52 & 26 \\
\hline & Toplam & 200 & 100 & & 3. Sinif & 74 & 37 \\
\hline \multirow{7}{*}{ 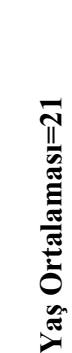 } & 18 & 8 & 4 & & 4. Sinif & 46 & 23 \\
\hline & 19 & 18 & 9 & & Toplam & 200 & 100 \\
\hline & 20 & 40 & 20 & \multirow{5}{*}{ 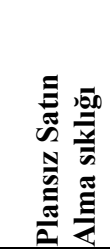 } & Sik sik & 41 & 20,5 \\
\hline & 21 & 62 & 31 & & Ara sira & 132 & 66 \\
\hline & 22 & 51 & 25,5 & & Hiçbir zaman & 27 & 13,5 \\
\hline & 23 ve üzeri & 21 & 10,5 & & Toplam & 200 & 100 \\
\hline & Toplam & 200 & 100 & & Elektronik Eşya & 28 & 6,6 \\
\hline
\end{tabular}


Tablo 1 Devamı: Katılımclların Demografik Özellikleri ve Plansı Satın Alma

\begin{tabular}{|c|c|c|c|c|c|c|c|}
\hline \multicolumn{8}{|c|}{ Niyeti } \\
\hline \multirow{8}{*}{ 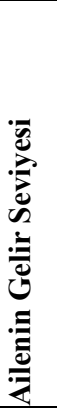 } & 1000 TL den az & 22 & 11 & \multirow{8}{*}{ 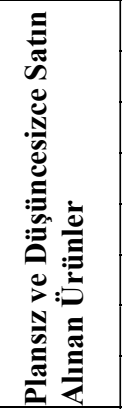 } & Kişisel Bakım & 76 & 17,9 \\
\hline & $1000-2000 \mathrm{TL}$ & 30 & 15 & & Giyim & 115 & 27,1 \\
\hline & 2001-3000TL & 48 & 24 & & Ev Dekorasyon & 16 & 3,8 \\
\hline & 3001-4000TL & 38 & 19 & & Gida & 86 & 20,2 \\
\hline & 4001-5000TL & 33 & 16,5 & & Kirtasiye & 39 & 9,2 \\
\hline & 5001-6000TL & 18 & 9 & & Eğlence Hizmeti & 44 & 10,4 \\
\hline & 6001 ve Üstü & 11 & 5,5 & & Diğger & 21 & 4,9 \\
\hline & Toplam & 200 & 100 & & Toplam & 425 & 100 \\
\hline \multirow{4}{*}{ 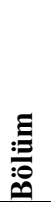 } & Bankacılık ve Finans & 71 & 35,5 & \multirow{4}{*}{ 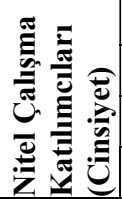 } & Kadın & 16 & 53,4 \\
\hline & İşletme & 29 & 14,5 & & Erkek & 14 & 46,6 \\
\hline & Sosyal Hizmet & 100 & 50 & & Toplam & 30 & 100 \\
\hline & Toplam & 200 & 100 & & & & \\
\hline
\end{tabular}

Katılımcıların demografik özellikleri ve satın alma davranışlarına yönelik bulgular Tablo 1'de verilmektedir. Cinsiyet değişkeni itibari ile yapılan değerlendirmede kadın katılımcıların yoğun bir katılımı görülmektedir. $\mathrm{Bu}$ sonucun oluşmasına fakültede okuyan kız öğrencilerin yoğun olması etki etmiştir. Katılımcıların yaş ortalaması 21 olarak tespit edilmiştir. Yaş değişkeni itibariyle en yoğun katılımın 20-22 yaş aralığında olduğu tespit edilmiştir. Ailevi gelirler açısından değerlendirildiğinde 2000-4000 TL gelire sahip katılımcıların yoğun katılımı görülmektedir. Bölüm bazlı değerlendirmede bölümlerin yoğunluğu ile orantılı olarak sosyal hizmet öğrencileri ön plana çıkmaktadır. Sınıf olarak ise 3. sınıflar daha fazla katılım sağlamışlardır. Nitel çalışma kapsamında ise 14 erkek, 16 kız öğrenciyle görüşme gerçekleştirilmiştir.

Görüşmeler kapsamında öncelikle katılımcıların plansız satın alma davranışını işaret eden ifadeler değerlendirilmiştir. Burada katılımcıların önemli bir bölümünün belli aralıklarla da olsa plansız satın alma eylemine yöneldiği görülmektedir. Ne kadar aralıklarla anlık ve plansız alışverişler yaptığ 1 bir görüşmeciye sorulduğunda "Genellikle ayda bir yapıyorum böyle anlık alışverişleri”" (Meral, K.) diyen görüş̧mecinin yanında farklı bir görüşmeci "Her gün alışveriş yaptığım da oluyor" (Metehan, E.) diyerek sürecin ne kadar değişken olabileceğini göstermiştir. Ancak bir görüşmeci, "Hiç almam hatta almamaya çalışırım, öğrenciyim ben çünkü" (Dilan, K.) diyerek anlık alışverişten kaçındığını belirtmiştir.

Görüşmeler sırasında bir görüşmeci ise plansız bir şeyler almak şöyle dursun plansız bir şeyler seçme hissine bile her an ihtiyaç olduğunu belirtmiştir. "Alışveriş sitelerine girip ürün favorilemek bile her an yaptığım bir şey, çünkü alışveriş yapmaktan büyük haz duyuyorum" (Ülkü, K). Planlamadan alışveriş yapmayı bir koşula bağlayan bir görüşmeci ise "Yeterli bütçem ve yanımda 
samimi arkadaşlarım olunca anlık bir şeyler alabilirim" (Ahmet, E.) demiştir. Son olarak plansız alışveriş için koşulların belirleyici olduğu fikrine katılan diğer bir görüşmeci ise "anlık bir şey almak benim için o gün havanın güzel olmasına, alışverişe kimle çıktığıma, kimlerle karşılaştığıma ve günümü nasıl bitireceğime bağlı" diyerek alışveriş kararını günlük plana bağladığını ifade etmiştir (Muhammed, E.).

Erkekler alışverişi, kişilere durumlara bağlayabilir. Bu durum kadınlarda da geçerli olabilir. Ancak kadınlar, plansız alışverişi olumsuz ruh haline bağlarken erkekler olumlu ruh halinin onları anlık alışverişe yönlendirdiğini belirtmişlerdir. Ayrıca kadınlar, bu durumun belirli aralıklarla gerçekleştiğini ifade etmekten kaçınmazken erkeklerin zaman konusunda net ifadelerinin olmadığı görülmüştür. Bu da kadının toplumsal roller açısından planlı duruşunu gösterirken erkeğin, davranışlarında duygu durumunun belirleyici olduğunu göstermektedir.

Görüşmeler sırasında plansız satın alma davranışının bir çekiciliği olduğu ve bu çekiciliğin de bireylerde yarattığı hisle alakalı olduğu görülmüştür. Böylelikle görüşmeciler, plansız alışveriş davranışını, öncesinde ve sonucunda hissedecekleri duygu için gerçekleştirebilirler ancak bu hissin değişkenliği kadın veya erkek fark etmeden eşit bir şekilde yaşanmaktadır. Örneğin kadın bir görüşmeci, "S1kılınca ya da moralim bozulunca mutlu olmak için anlık şeyler alabiliyorum" (Ülkü, K) derken alışveriş öncesi duygu durumunun onu yönlendirdiğini işaret etmektedir. Erkek bir görüşmeci ise "İyi bir alışveriş yaptığımda bende endorfin hormonu tavan yapıyor. Yani sanki 100 tane bitter çikolata üst üste yemiş gibi oluyorum" (Kerem, E.) diyerek plansız alışveriş sonucundaki duygu durumunu işaret etmiş̧tir. $O$ halde bu noktada kadın görüşmecilerin alı̧̧veriş öncesi beklentiye girerken erkek görüşmecilerin alışveriş sonrasında hissedeceklerine yoğunlaştıkları söylenebilir.

Görüşmeler sırasında bazı görüşmeciler, sırf alışveriş sonunda duydukları his sebebiyle anlık alışverişten kaçındıklarını belirtmişlerdir. Bu durum kadın ve erkek için de geçerlidir. "Anlık bir şeyler aldıktan sonra pişmanlık çok yaşıyorum. Örneğin bir arkadaşıma indirimde bir pantolon görüp almıştım ama o pantolon arkadaşımın tarzı değilmiş. İade etmek zorunda kaldım." (Yunus Emre, E.) diyen erkek bir görüşmecinin yanında "Bir keresinde çok gereksiz bir şekilde 6 tane bandana almıştım. Renkleri farklı ama modelleri aynıydı. Pişman oldum" (Dilan, K) diyen kadın görüşmecinin sırf anlık satın alma davranışı sonucunda ortaya çıkacak hisle bir sonraki alışverişlerinde plansız alışverişten kaçındıkları ortaya çıkmıştır.

Plansız satın alma davranışının genellikle giyim, gıda ve kişisel bakım ürünlerine yönelik gerçekleştirildiği görülmektedir. Söz konusu durum, kadın ve erkeklerde farklılık yaratmamaktadır. "Tabi oluyor. Aklımda bir şey almak yoktu. Girdim elbise aldım."(Meral, K.). Anlık satın alma davranışının dış görünüşe etki eden nesneler üzerinden yapılmasının nedenini karşı cinsi etkilemeye bağlayan bir erkek görüşmeci, dış görünüşe yönelik harcamayı şöyle açıklar; "Her erkeğin 


\section{Toplumsal Cinsiyet Rolleri ve Tüketim Kültürü}

fitratında karşı tarafı etkilemek vardır. Bu durum kadınlar için de geçerli. O yüzden alışveriş yaparken giyime yöneliyoruz. Hayal kuruyoruz ve hayalimizdeki tarzı yakalamak istiyoruz. Tabi ki hayalimizdeki kişinin dış görüşüne benzemeye çalışıyoruz (Metehan, E). Görüşmeler sırasında sadece bir erkek görüşmeci, yatırım maksatlı bir takım alımlar yaptığını belirtmiştir. Bu durum onun için anlık satın almadır. "Anlık, hisse senedi alıyorum" (Burak, E.). $\mathrm{Bu}$ görüşmeci, diğer 29 görüşmeciden farklı bir tüketim malzemesinden söz etmiştir. Neticede diğer görüşmecilerin tümü dış görünüş için gerekli nesnelerden bahsetmiștir.

\subsection{Faktör Analizine Yönelik Bulgular}

Katılımcıların hedonik tüketim ve plansız satın alma eylemine yönelik eğilimlerini belirlemek için farklı iki ölçekten faydalanılmıştır. Ölçeğin araştırma için uygun ve örneklemin yeterli olup olmadığını test etmek için açıklayıcı faktör analizi gerçekleştirilmiştir. Bu kapsamda hedonik tüketim ölçeğine yönelik açıklayıcı faktör analizi aşağıdaki tabloda gösterilmektedir.

Tablo 2: Hedonik Tüketim Ölçeği Faktör Analizi

\begin{tabular}{|c|c|c|c|c|}
\hline $\begin{array}{l}\text { Bana göre alışveriş en iyi stres atma } \\
\text { yöntemidir }\end{array}$ & ב,853 & & & \\
\hline Benim için alışveriş coşku verici bir olaydır & 844 & & & \\
\hline $\begin{array}{l}\text { Alışverişe çıktığım zaman kendimi başka } \\
\text { bir dünyada ve çok güçlü hissederim. }\end{array}$ & 824 & & & \\
\hline $\begin{array}{l}\text { Kendimi mutlu etmek istediğimde } \\
\text { alışverişe çıkarım }\end{array}$ & 805 & & & \\
\hline $\begin{array}{l}\text { Moralim bozuk olduğunda alışverişe } \\
\text { çıkmak kendimi daha iyi hissetmemi sağlar }\end{array}$ & ,764 & & & \\
\hline $\begin{array}{l}\text { Alışveriş yapmak bana her zaman için ilgi } \\
\text { çekici gelmiştir. }\end{array}$ & ,751 & & & \\
\hline Bana göre alışveriş bir maceradır & 698 & & & \\
\hline $\begin{array}{l}\text { Alışverişe son modayı takip etmek için } \\
\text { çıarım }\end{array}$ & & ,856 & & \\
\hline $\begin{array}{l}\text { Alışverişe piyasadaki en son ürünleri } \\
\text { görmek için çıkarım. }\end{array}$ & & ,826 & & \\
\hline $\begin{array}{l}\text { Alışverişe en son eğilim ve tercihlerden } \\
\text { haberdar olmak için çıkarım }\end{array}$ & & ,715 & & \\
\hline $\begin{array}{l}\text { Alışverişe kendimce yeni şeyler denemek } \\
\text { için çıkarım. }\end{array}$ & & ,527 & & \\
\hline $\begin{array}{l}\text { Alışverişe çoğunlukla } \\
\text { zamanlarında çıarım. }\end{array}$ & & & 807 & \\
\hline $\begin{array}{l}\text { Alışverişe çıktığımda indirimli ürünleri } \\
\text { arayıp bulmak hoşuma gider }\end{array}$ & & & ,791 & \\
\hline $\begin{array}{lrr}\text { Alışverişe indirim } & \text { zamanlarının } \\
\text { avantajlarından faydalanmak için giderim }\end{array}$ & & & ,682 & \\
\hline
\end{tabular}


Tablo 2 Devamı: Hedonik Tüketim Ölçeği Faktör Analizi

\begin{tabular}{|c|c|c|c|c|c|}
\hline $\begin{array}{l}\text { Alışverişe çıktığımda indirimdeki ürünleri } \\
\text { başkalarından önce yakalayıp bulmaktan } \\
\text { çok zevk alırım. }\end{array}$ & & & ,627 & & \\
\hline $\begin{array}{l}\text { Bana göre tanıdıklarla alışverişe çıkmak } \\
\text { onlarla eğlenceli vakit geçirmek için bir } \\
\text { firsattır. }\end{array}$ & & & & 845 & \\
\hline $\begin{array}{l}\text { Bana göre tanıdıklarla alışverişe çıkmak } \\
\text { yeni paylaşımlar yaşamaktır. }\end{array}$ & & & & ,818 & \\
\hline $\begin{array}{l}\text { Alışverişe gittiğimde diğer insanlarla } \\
\text { etkileşime girmekten zevk alırım. }\end{array}$ & & & & ,721 & \\
\hline $\begin{array}{l}\text { Alışverişe ailemle ya da arkadaşlarımla } \\
\text { etkileşimde bulunmak, sosyalleşmek için } \\
\text { giderim }\end{array}$ & & & & ,517 & \\
\hline $\begin{array}{l}\text { Ailem ve arkadaşlarım için alışveriş } \\
\text { yapmaktan zevk alırım }\end{array}$ & & & & & ,868 \\
\hline $\begin{array}{l}\text { Hayatımdaki özel insanlar için alışveriş } \\
\text { yaptı̆̆ımda kendimi daha iyi hissederim. }\end{array}$ & & & & & ,790 \\
\hline $\begin{array}{l}\text { Hediye alırken mükemmeli bulmak için } \\
\text { zaman ve çaba harcamaktan çok } \\
\text { hoşlanırım. }\end{array}$ & & & & & ,728 \\
\hline $\begin{array}{l}\text { Alışverişe başkalarına bir şeyler satın } \\
\text { almak için giderim. Çünkü onlar mutlu } \\
\text { olduklarında ben de mutlu olurum }\end{array}$ & & & & & ,507 \\
\hline Açıklanan Varyans & 36,1 & 12,4 & 9,3 & 6,4 & 6,1 \\
\hline Kümülatif Açıklanan Varyans & 36,1 & 48,4 & 57,8 & 64,1 & 70,2 \\
\hline Güvenilirlik \% - Cronbach's Alpha & ,932 & ,821 & ,824 & ,826 & ,761 \\
\hline
\end{tabular}

Tablo 2'de katılımcıların hedonik davranışlarının ölçümüne yönelik 23 maddeden oluşan ölçek bulunmaktadır. Ölçeğe yönelik yapılan birinci aşama faktör analizinde ideal faktör yapısına ulaşılmıştır. Yapılan analiz sonucunda KMO değeri (0.858) ve Barlett Test değeri $(2824 ; 169)$ olarak tespit edilmiştir. $\mathrm{Bu}$ sonuca göre, verilerin faktör analizine uygun, örnek hacmi ise yeterlidir. Faktör analizi sonucunda 5 boyuttan oluşan bir yapı oluşmuştur. Orijinal ölçekte farklı iki boyut olan macera ve rahatlama boyutları bu çalışmada tek boyutta toplanmıştır. Böylece edilen 5 boyut, macera ve rahatlama, fikir edinme, firsatları yakalama, sosyalleşme ve başkalarını mutlu etme olarak isimlendirilmiştir. Boyutlar toplam varyansın \%70,2'sini açılamaktadır. Aynı zamanda tüm boyutların yüksek derecede güvenilir olduğu tespit edilmiştir.

Plansız satın alma ölçeğinin geçerliliğini test etmek için açıklayıcı faktör analizi yapılmıştır. Tablo 3'te bu ölçeğe yönelik faktör analizi sonuçları gösterilmektedir. 
Tablo 3: Plansız Satın Alma Ölçeği Faktör Analizi Sonuçları

\begin{tabular}{|l|l|}
\hline İfadeler & Plansız Satın Alma \\
\hline Plansız satın almalar yapan biriyimdir. &, 879 \\
\hline $\begin{array}{l}\text { Gerçekten ilginç bir şey gördüğ̈̈mde sonuçlarını } \\
\text { düşünmeksizin onu satın alırım. }\end{array}$ &, 834 \\
\hline Sebepsiz olarak satın almak eğlencelidir. &, 808 \\
\hline $\begin{array}{l}\text { Alışverişe çıktığımda almaya niyetim olmayan bazı şeyleri } \\
\text { satın alırım }\end{array}$ &, 778 \\
\hline Alışveriş listemde olmayan şeyleri almaktan kaçınırım &, 612 \\
\hline Açılanan Varyans & 62,01 \\
\hline Güvenilirlik \% - Cronbach's Alpha &, 596 \\
\hline KMO=762; Barlett=452,013; (df= 10); P=000 \\
\hline
\end{tabular}

5 değişkenden oluşan plansız satın alma ölçeğine uygulanan faktör analizi sonucunda tüm değişkenlerin tek boyutta toplandığı görülmüştür. Yapılan analiz sonucunda KMO değeri $(0.762)$ ve Barlett Test değeri $(452,013)$ olarak tespit edilmiştir. $\mathrm{Bu}$ sonuca göre, verilerin faktör analizine uygun, örnek hacmi ise yeterli olduğu görülmektedir. Boyut ifadeleri toplam varyansın \%62,01'ini açılamaktadır. Aynı zamanda ölçeğin yeterli oranda güvenilir olduğu tespit edilmiştir.

\section{3. Ölçek Boyutlarına Yönelik Tanımlayıcı İstatistikler}

Katılımcıların ölçek boyutlarına yönelik görüşlerini içeren tanımlayıcı istatistikler Tablo 4'te verilmektedir.

Tablo 4: Ölçek ve Boyutlara Yönelik Tanımlayıcı İstatistikler

\begin{tabular}{|l|l|}
\hline Ölçek/Boyutlar & Ortalama \\
\hline Macera ve Rahatlama & 3.2695 \\
\hline Fikir Edinme & 2.8249 \\
\hline Fırsatları Yakalama & 3.6849 \\
\hline Sosyalleşme & 3.2371 \\
\hline Başkalarını Mutlu Etme & 3.7953 \\
\hline Plansız Satın Alma Ölçeği & 3.0184 \\
\hline
\end{tabular}

Yukarıdaki tablodan da görüleceği üzere katılımcıların hedonik tüketim eğilimleri ve plansız satın alma davranışları genel olarak ortalamanın üzerindedir. Bu kapsamda katılımcılar tarafından en fazla önemsenen hedonik tüketim boyutu başkalarını mutlu etme, en az önemsenen hedonik tüketim boyutu ise fikir edinme boyutudur.

Görüşmeler sırasında aile ve akrabalık bağlarının, tüketicileri plansız satın alma eğiliminde bulunmaya yönlendirdiği görülmüştür. Hedonik tüketimin başkalarını mutlu etme boyutuna örnek olarak bir görüşmeci; "Mesela okul tatil olunca eve giderken elim dolu olsun diye hediye aldım evdekilere" (Meral, K.) diyerek başkalarını mutlu etmek adına plansız alışverişte bulunduğunu 
belirtmiştir. "Kendim için değil ama arkadaşım için o anda bir şeyler alabilirim. Örneğin bir tatlıcının önünden geçerken arkadaşımın sevdiği tatlıyı alabilirim" (İbrahim, E.) diyen bir görüşmeci de arkadaşını mutlu etmek için anlık tüketimde bulunduğundan bahsetmiştir. Görüşmeler sırasında sadece bir kadın görüşmeci, "Ben başkalarını mutlu etmek için alışveriş yapmam sadece kendime alırım" diyerek alışverişte "başkalarını mutlu etmekten" kaçındığını belirtmiştir (Zeynep, $\mathrm{K})$. Ona göre bunun sebebi "ben sadece ihtiyaçlar için alışveriş yaparım" ifadesinde görülebilir.

Hedonik tüketimin en az önemsenen boyutu ise fikir edinmedir. Teknolojinin gelişmesi ile birlikte ortaya çıkan iletişim imkânları insanları mağaza mağaza gezmeden çeşitli platformlar aracılığıyla araştırma yapmaya yönlendirmiştir. Bu durumun kişileri fikir edinmek için satın alma eyleminden bir nebze olsun uzaklaştırdığı düşünülmektedir. Özellikle görüşmeler sırasında bir kadın görüşmeci "şal sayfalarını takip ettiğim için sürekli yeni şal modelleri geliyor. Yeni modeller geldiğinde haberdar olmak istiyorum. Ancak benzerleri bende olsa da almak istiyorum" (Semanur, K.)diyerek fikir almak için internetten yararlandığını bu durumun da görüşmeciyi satın alma davranışına yönlendirdiğini belirtmiştir. Görüşmeler sırasında bu kadın görüşmeci dışında hiçbir kadın ya da erkek görüşmeci alışverişte fikir alma konusuna değinmemiştir.

\section{4. Ölçeklere Yönelik Farklılık Analizleri}

Katılımcıların hedonik tüketim ve plansız satın alma eğilimlerinin cinsiyet ve diğer demografik özellikler itibariyle farklılaşıp farklılaşmadığı bağımsız iki örneklem t-testi ve tek yönlü varyans analizi ile test edilmiştir. Öncelikle cinsiyet değişkeni itibariyle hedonik tüketim ve plansız satın alma davranışlarının farklılaşıp farklılaşmadığı bağımsız iki örneklem t-testi ile test edilmiştir.

Yapılan test sonucunda hedonik tüketim boyutlarından macera ve rahatlama $(\mathrm{P}=0.000$, Ort. Kadın=3.550, Ort. Erkek=2.627), firsatları yakalama $(\mathrm{P}=0.000$, Ort. Kadın=3.828, Ort. Erkek=3.351) ve başkalarını mutlu etme $(\mathrm{P}=$ 0.000 , Ort. Kadın=3.953, Ort. Erkek=3.426) boyutlarının cinsiyet itibariyle farklılaştı̆̆ 1 tespit edilmiştir. Bu sonuca göre kadınlar erkeklerden daha fazla macera ve rahatlama, firsatları yakalama ve başkalarını mutlu etmek için alışverişe yönelmektedir.

Görüşmeler sırasında kadın görüşmecilerin alışverişi rahatlamak için yaptığına örnekler verilebilir. "Ben alışveriş yaptığımda rahatlama hissi oluyor. Kendimi inanılmaz şekilde güvende hissediyorum" (Kübra, K) diyen kadın görüşmeciye "Ben alışverişi zevk almak ve oradan mutlu çıkmak için yaparım" diyen erkek bir görüşmecinin fikirleri de eklenebilir. Ancak belirtilmelidir ki araştırma sırasında sadece iki erkek görüşmeci rahatlama hissini ön plana çıkararak alışveriş yaptığından bahsetmiştir. "Genellikle bir ihtiyacım olduğunda alışveriş yaparım, rahatlamak ya da macera olsun diye yapmam" (Muhammed Ali, E.). Erkeklerin macera ve rahatlama hissiyle alışveriş yapmaktan kaçınmalarının sebebi ihtiyaca yönelik alışveriş yaptıklarını ifade etmeleridir. 


\section{Toplumsal Cinsiyet Rolleri ve Tüketim Kültürü}

Başkalarını mutlu etme boyutunda sadece bir kadın görüşmecinin başkalarını mutlu etmekten kaçındığı ifadelerinin yanında firsatları yakalama boyutu söz konusu olduğunda kadın görüşmecilerin ve erkek görüşmecilerin alışverişte firsatları değerlendirmeye çalıştığı görülmektedir. Ancak erkek görüşmeciler, firsatları değerlendirme konusunda kadınlar kadar iddialı ya da davranışa yönelik olmadığı görülmektedir. Örneğin bir erkek görüşmeci "Alışverişte firsatları yakalamaya çalışırım ancak çoğu zaman yakalayamam" (Halil, E) diyerek fursatlar için istekli olduğunu ancak bu isteği satın alma davranışına dönüştüremediğini belirtmiştir.

Görüşmelerde kadın görüşmeciler firsatları yakalamada ne kadar başarılı olduğunu ispat etmeye çalışmışlardır. " Bazı marketlere haftalık gelen firsat

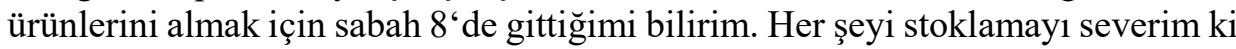
içinde bulunduğumuz kriz dönemlerinde bu stoklarım çokça işe yaradı". (Zehra, K) Kadınların firsatları değerlendirmede erkeklerden önde olmasının sebebi ise fırsatları yakalamanın verdiği hissi kadınların rahatlama erkeklerin ise pişmanlık olarak değerlendirmesidir. "Pahalı olan bir şeyi indirimden almak insana büyük rahatlık verdiğinden firsatları değerlendiriyorum" (Sida, K). Diyen bir kadın görüşmecinin aksine erkek görüşmeci, "ihtiyaçlarıma göre alıyorum çünkü fırsatları yakalarım diye istemediğim şeyleri alıp pişman olabiliyorum" (Ahmet, E) şeklinde cevap vermiştir.

Aynı zamanda cinsiyet itibariyle plansız satın alma davranışının da farklılaştı̆̆ görülmektedir. Bu kapsamda yapılan test sonucunda $(\mathrm{P}=0.000$, Ort. Kadın=3.315, Ort. Erkek=2.667) bulgulara ulaşılmıştır. Bu sonuca göre kadınlar, erkeklere nazaran daha fazla plansız satın alma eylemine yönelmektedir. Böyle bir sonucun ortaya çıkmasında kadınların "kasa önünde ödemeye gittiğimde oradaki ürünler arasında indirimde olanlar varsa alıyorum" (Keriman, K); "Moralim çok bozuk olduğunda rahatlamak için alıyorum" (Fulya, K); "Yeni ve güzel şeyler insanları mutlu ettiği için istemeden de aldığım şeyler oluyor" (Feyza, K); "Yorgun olduğumda yeni şeyler alıyorum. Dinlenme hissi veriyor" (Tuba, K) gibi ifadeleri örnek olarak sunulabilir. Kadınların rahatlama ya da içinde bulundukları ruh halinden kaçmak için satın almaya yöneldikleri söylenebilir. Bunun yanında erkekler için yine "ihtiyacımı alıyorum sadece" (Mazlum, E) ve "sevgilimden ayrıldı ğımda plansız bir şekilde şaçma sapan şeyler aldım ondan dolayı ihtiyacım oldukça almaya çalışıyorum" (Serhat, E) gibi ifadeler, erkek görüşmecilerin plansız satın alma davranışından kaçınma sebebini ihtiyaç dışı olarak görmeleri şeklinde düşünülebilir. Buna göre kadınlar plansız satın almayı bir duygu durum sonucu olarak değerlendirirken erkekler, alışveriş ile belirli bir duygu durumunu bağdaştıramamışlardır. Bu durumun sebebi erkeklerin ve kadınların alışverişi farklı şekilde tanımlamalarından kaynaklanabilir. Kadın ve erkeklerin ihtiyaç kavramını farklı şekilde tanımlamaları, bireylerin alışverişe yönelmelerini de olumlu veya olumsuz şekilde etkilemiştir. 
$\mathrm{Bu}$ noktada ayrıntıya inmek gerekirse sıkça plansız ve hedonik satın almada bulunan bir görüşmeci ihtiyaç kavramını, " Benim için ihtiyaç her şeydir. $\mathrm{O}$ an bulunduğum ruh halimde canım neyi isterse elde etmek istediğim şeydir "(Ülkü, K) şeklinde tanımlarken; plansız satın almadan kaçınmaya çalışan bir kadın görüşmeci ihtiyaç kavramını "müsrif olan ya da parası fazla olanların sıkça yaptığı şey boşuna alışveriş yapmak işte ihtiyaç dediğimizde bu olmaması gerekiyor" (Feyza, K) şeklinde tanımlamıştır. Burada görülmektedir ki sadece erkek ve kadın arasında değil kadın görüşmecilerin kendi aralarında da ihtiyacı farklı şekillerde yorumlamaktan kaynaklanan satın alma davranışı farklılıkları söz konusudur. Ancak erkek görüşmecilerin arasında ihtiyaç tanımlamasında bu şekilde belirgin bir farklılık söz konusu değildir. "Yaşamın idamesi için yapılan maddi manevi her şey ihtiyaçtır" (İbrahim, E) ifadesi erkekler için benzer ihtiyaç tanımlarının ortak şeklidir denilebilir.

\section{Sonuç ve Öneriler}

Yapılan çalışmada plansız bir şekilde satın alma davranışının katılımcılar arasında değişiklik gösterdiği ortaya çıkmıştır. Görüşmecilerin cinsiyeti bu konuda ayrım yapılmasına izin vermemektedir. Bazı kadın görüşmeciler, plansız satın almayı kabul ederken bazıları ekonomik anlamda yetersiz olduğunu vurgulayarak plansız alışverişten kaçındıklarını belirtmişlerdir. Bu durum, kadın görüşmecilerin plansız alışveriş söz konusu olduğunda genelleştirilemeyeceğini ortaya koymaktadır ancak erkek görüşmeciler, plansız alışveriş konusuna daha net bir tavırla yaklaşmakta ve plansız alışverişten kaçınmaktadırlar.

Erkek görüşmeciler, alışverişleri sırasında "ihtiyaç" kavramının altını çizmektedirler. Onlara göre bir şeyi planlamadan satın almak gibi bir durum söz konusu değildir. Böyle olduğunda alışverişin sonu pişmanlık olabilmektedir. Aslında pişmanlık konusu kadın görüşmecilerde de sıklıkla karşılaşılmaktadır. Ancak kadın görüşmeciler duygu durumları onları alışverişe yönlendirdiği için doğru düşünememekte ve pişmanlık duyabilecekleri bir alışveriş gerçekleştirebileceklerini belirtmişlerdir. Ayrıca kadın görüşmecilerin bir kısmı plansız alışverişi, mutsuz oldukları durumlarda psikolojik etkileri olumlu olabilecek bir ihtiyaç olarak görmektedirler.

Erkek görüşmecilerin alışverişe çıkma konusunda ihtiyaçlardan hareket etmesi onların plansız satın alma davranışını düzenlerken kadınlardan farklı olarak alışverişin sonucuna odaklanmalarına neden olmaktadır. Dolayısıyla denilebilir ki tüketim kültürünün öncelikli olarak kadını hedef alması, kadının alışverişe gitmeden önce duygu durumunun yönlendirmesine kapılması ile alakalıdır. Bu sebeple kadın görüşmecilerin neredeyse tümünde "mutsuzsam alışverişe çıkarım” fikri baskındır. Bu ifade, tüketim kültürünün kadın tüketicileri erkeklere göre daha çabuk etkisi altına almasına neden olmaktadır.

Erkek görüşmecilerde "ihtiyacım varsa alışverişe çıkarım" fikri ön plandadır. Bu durum, erkek görüşmecilerin "sonuç odaklı bakış açısının" tüketim kültürünün etkilerine kadınlar kadar açık olmadığını göstermektedir. Bu durum 


\section{Toplumsal Cinsiyet Rolleri ve Tüketim Kültürü}

hem kadının hem de erkeğin "ihtiyaç" kavramını nasıl anlamlandırdığ 1 ile bağlantılıdır. Aslında her iki taraf da ihtiyaçlarını gidermek için alışverişe çıkmaktadır. Sadece kadınlar, "mutsuz" olunan zamanlarda "alışverişı”" ihtiyaç olarak görmektedirler. Bu ihtiyaç ise "mutlu" olma ihtiyacıdır.

Literatürde yer alan ve Bauman (2018)'ın ifade ettiği avcının tavşanın peşinde koşma sırasında hissettiği duygu durumu daha çok kadının kapıldığı bir durum olabilir ya da mutsuz olduğu bir anda kadının, söz konusu "curcuna ve telaşa" kapılması mutsuzluğunun yerine tercih ettiği bir durum olarak da düşünebilir. $\mathrm{O}$ halde denilebilir ki erkek, mutsuzluk ile farklı yollardan başa çıkabilir ancak kadın için bu durum, tüketim kültürünün verdiği his ile geçiştirilebilecek şekilde anlamlandırılmaktadır.

Çalışmada "pişmanlık" ve "mutluluk" kavramları üzerinde duran görüşmecilerden erkek görüşmeciler, plansız alışverişlerini "pişmanlık" kavramı ile anlatırken; kadın görüşmeciler, "mutluluk" kavramını kullanmayı tercih etmiş̧lerdir denilebilir. Tabi ki araştırma evreni üniversite öğrencilerinden oluştuğundan bu sonuç genel tüketici davranışı olarak genellenemez. Bu açıdan bundan sonra yapılacak olan çalışmalara bir öneri olarak farklı yaş gruplarından seçilecek görüşmecilerin " plansız satın almaya ve hedonik tüketime" nasıl yorumlar yapabileceği önem kazanmıştır.

Yapılacak olan nitel çalışmalarda "kadınların mutlu olmak ve mutlu etmek için tüketimi tercih etmelerinin nedeni sorgulanabilecekken; erkeklerin de "ihtiyaç" olarak gördükleri evrenin sınırları çizilip farklı ihtiyaç tanımlamaları yapılabilecektir. Ayrıca kadınlık ve erkeklik rollerinin tüketime yansıması ve tüketici eğilimlerinin neler üzerinde yoğunlaştı̆̆ını anlamak açısından toplumsal cinsiyet rollerinin ve tüketim davranışlarının nicel ve nitel araştırma tekniklerinin her ikisinden yararlanılarak karma araştırma yönteminin kullanılması önerilmektedir.

Son olarak dünyada, tüketim eğilimleri ve toplumsal cinsiyet rollerini konu alan araştırmalar sıklıkla yapılmaktadır ancak Türkiye özelinde de disiplinlerarası çalışmaların yapılması önerilmektedir. Böylelikle tüketim kültürünün şekillendirdiği sosyal dünyayı anlamak açısından tüketim konusuna çoklu bir perspektiften bakılabilecektir.

\section{Kaynaklar}

Açıkalın, S., Yaşar, M. (2017), Tüketim Bağlamında Tüketici Davranışlarının İncelenmesi: Gençlerin Hedonik Tüketim Eğilimlerini Belirlemeye Yönelik Bir Araştırma, Uluslararası Sosyal Araştırmalar Dergisi, 10(48), $570-585$.

Akturan, U. (2010), Hedonik Tüketim Eğiliminin Plansız Satın Alma eğilimi Üzerindeki Etkisinin Belirlenmesi, Öneri Dergisi, 9(33), 109-116.

Altunışık, R., Çallı, L. (2004), Plansız Alışveriş (Impulse Buying) ve Hazcı Tüketim Davranışları Üzerine Bir Araştırma: Satın alma Karar Sürecinde 
Bilgi Kullanımı, 3. Ulusal Bilgi, Ekonomi ve Yönetim Kongresi, 25-26 Kasım, Eskişehir.

Armağan, E., Danışman, E. ve Öngen, H. B., (2019), Sanal Mağaza Atmosferinin Anlık Satın Almaya Etkisi, Atatürk Üniversitesi Iktisadi ve İdari Bilimler Dergisi, 1(33), 29-49.

Arnold, Mark J., Reynolds, Kristy E. (2003), Hedonic Shopping Motivations, Journal Of Retailing, 79(2), 77-95.

Aydın, S. (2010), Hedonik Alışverişin Cinsiyet, Gelir Ve Yerleşim Büyüklügüne Göre Farklılaşması Üzerine Bir Araştırma, Süleyman Demirel Üniversitesi İktisadi ve İdari Bilimler Fakültesi Dergisi, 15(3), 435-452.

Aytekin, A. (2015), Hedonik Tüketim ve Anlık Satın Alma İlişkisi, Niğde Üniversitesi Iktisadi ve İdari Bilimler Fakültesi Dergisi, 8(1), 141-156.

Babacan, M. (2001), "Hedonik Tüketim ve Özel Günler Alışverişlerine Yansıması", 6. Ulusal Pazarlama Kongresi Bildiri Kitab1, Atatürk Üniversitesi, İ̈BF, Erzurum, ss. 97-106.

Baudrillard, J. (2004), Tüketim Toplumu. (Çev: Hazal Deliceçaylı, Ferda Keskin). İstanbul: Ayrıntı Yayınları.

Bauman, Z. (2018), Kuşatılmış Toplum (Çev: Akın Emre Pilgir), İstanbul: Ayrıntı Yayınları.

Bocock, R. (2014), Tüketim. (Çev. İ. Kutluk), Ankara: Dost Yayınevi.

Bulut, Z. A., Çımrin Kökalan, F. ve Doğan, O. (2017), Gender, generation and sustainable consumption: Exploring the behaviour of consumers from Izmir, Turkey, International IJC, 41, 597-604.

Butler, J. (2012), Cinsiyet Belası, Feminizm ve Kimliğin Altüst Edilmesi, (Çev. Başak Ertür), İstanbul: Metis Yayınları.

Chang, E. (2001), The Mediating Role of Hedonic Shopping Value in Apperal Shopping Satisfaction, Submitted to Oregon State University in Partial Fullfillment of the Requirements for the Degree of Doctor of Philosophy.

Çakıcı, A. C., Özdamar, M. (2014), Şanlıurfa'da Kültür Turlarına Katılan Yerli Turistlerin Anlık Satın Alma Davranışları Üzerine Bir Araştırma, Balikesir University The Journal of Social Sciences Institute, 17(31), 287-306.

De Beauvoir, S. (1993), Kadın "İkinci Cins" I, (Çev. Bertan Onaran). İstanbul: Payel Yayınları.

Doğan, H. G., Gürler, A. Z. ve Ağcadağ, D. (2014), Hedonik Tüketim Alışkanlıkları Üzerine Etkili Faktörlerin Değerlendirilmesi (Tokat İli Örneği), Uluslararası Sosyal Araştırmalar Dergisi, 7(30), 69-77.

Erciş, A., Deligöz, K., ve Özkan, B. S. (2019). The Effect of Exploratory Buyıng on Impulse Buying Behavior: The Role of Hedonic Consumption. The Journal of International Social Research, 12, 1120-1130.

Ferguson, H. (1996), The Lure of Dreams: Sigmund Freud and The Construction Of Modernity, London: Routledge.

Gegez, E. (2010), Pazarlama Araştırmaları. İstanbul: Beta Yayınları. 
Karaca, Ş. (2019), Materyalist Eğilimlerin Anlık Satın Alma Davranışına Etkisinin İncelenmesi: Üniversite Öğrencilerine Yönelik Bir Çalışma, Üçüncü Sektör Sosyal Ekonomi Dergisi, 54(1), 243-260.

Kim, H. (2019), An Analysis in Preference of Coffee Consumption by Gender and Age, Culinary Science \& Hospitality Research, 25(9), 129-134.

Köroğlu, M. A. (2014), Tüketim Kültürünün Gençliğe Etkisi Üzerine Bir Değerlendirme. Gümüşhane Üniversitesi İletişim Fakültesi Dergisi, 4(2), 254-269.

Kükrer, Ö. (2011), Üniversite Öğrencilerinde Hedonik Tüketimin Cinsiyete Göre Farklılaşması, Karadeniz Teknik Üniversitesi İletişim Araştırmaları Dergisi, 1, 78-87.

Levy, Sidney J. (1959), SymbolsforSale, Harvard Busi- ness Review, 37 (JulyAugust), 117- 119.

Odabaşı, Y., ve Barış, G., (2006), Tüketici Davranışı, Kapital Medya Hizmetleri A.Ş., İstanbul.

Özdemir, Ş., Yaman, F. (2007), Hedonik Alışverişin Cinsiyete Göre Farklılaşması Üzerine Bir Araştırma, Eskişehir Osmangazi Üniversitesi IIIBF Dergisi, 2(2), 81-91.

Özgüven, N. (2013), Hedonik Tüketim ile Cinsiyet ve Gelir Değişkenleri Arasındaki İlişkinin Analizi, Journal of SocialScience, 1(6), 169-180.

Rook D. W. (1987), Thebuyingimpulse, Journal of Consumer Research, 14, 189199.

Rook, D. W.,\& HochS. J. (1985), ConsumingImpulses. Advances in Consumer Research, 12, 23-27.

Schaugnessy J \& O'Schaugnessy N. (2002), Marketing the Consumer Societyand Hedonism, European Journal of Marketing, 35(5/6), 524-547.

Scherhorn, G., Reisch, L.A., Raab, G. (1990), AddictiveBuying in West Germany: An Emprical Study, Journal of Consumer Policy, 13(4), 355387.

Sormaz, F , Yüksel, H . (2012). Transforming Childhood, Industrialization of Play and Toys and Consumer Culture . Gaziantep University Journal of Social Sciences , 11 (3) , 985-1008 .

Stern, H. (April 1962), The Significance of Impulse Buying Today, Journal of Marketing, 59-62.

Şener, S. (1997), Türkiye ve Gençlik, İstanbul: Suffe Yayınları.

Tifferet, S., Herstein, R. (2012), Gender differences in brand commitment, impulse buying, and hedonic consumption, Journal of Product \& Brand Management, 21(3), 176-182.

Turner, B. S. (2011), Tıbbi Güç ve Toplumsal Bilgi. (Çev. Ü. Tatlıcan), Bursa: Sentez Yayıncilık.

Tükel, İ. (2014), Tüketimin Yeni Aktörleri:“Y Kuşağı”, Hacettepe Üniversitesi Sosyolojik Araştırmalar Elektronik Dergisi, 1-22. 
Weun, S., Jones, M. A. ve Beatty, S. E. (1997), A Parsimonious Scaleto Measure Impulse Buying Tendency, in W. M. Pride ve G. T. Hult (Eds.), Chicago: American Marketing Association: Enhancing knowledge development in marketing, 206-307.

Yiğit, M. K. (2014), Onlıne Anlık Satın Alma Davranışını Etkileyen Faktörlerin Pişmanlık Ve Tatmin Üzerindeki Etkisinde Marka Bilinirliliği Ve Marka Sadakatinin Aracı Rolü, Doktora Tezi. Marmara Üniversitesi Sosyal Bilimler Enstitüsü.

Yücel, E. K. (2018), Beyaz Eşya Ürünlerinde Toplumsal Cinsiyet Rollerinin Satın Alma Karar Tarzları Üzerine Etkisi, Dokuz Eylül Üniversitesi İktisadi ve İdari Bilimler Fakültesi Dergisi, 1(33), 319-352. 